\title{
GAMBARAN KUALITAS PELAYANAN OBAT PADA PASIEN BPJS DI DEPO FARMASI BLUD RSUD BALANGAN PERIODE MEI-JUNI TAHUN 2016
}

\author{
DESCRIPTION OF SERVICE QUALITY IN DRUGS IN \\ PATIENTS BPJS DEPO PHARMACEUTICAL BLUDS \\ HOSPITAL BALANGAN \\ PERIOD MAY - JUNE 2016
}

\author{
NoverdaAyuchecaria ${ }^{1}$, TansiaDiyanti ${ }^{1}$, Yugo Susanto ${ }^{1}$, Dulena Sandrainy $\mathbf{P}^{2}$ \\ ${ }^{1}$ Akademi Farmasi ISFI Banjarmasin, ${ }^{2}$ RSUD Balangan Kalimantan Selatan \\ Email : noverdaayu24@gmail.com
}

\begin{abstract}
ABSTRAK
Persepsi pasien tentang pelayanan memegang peranan yang sangat penting. Saat ini tingkat persaingan yang semakin ketat di kalangan usaha rumah sakit mempersyaratkan adanya daya saing bagi rumah sakit agar dapat memenangkan persaingan yang ada. Salah satu bentuk daya saing yang harus diciptakan oleh usaha rumah sakit adalah kualitas layanan. Tujuan penelitian ini untuk mengetahui kualitas pelayanan obat di Depo Farmasi BLUD RSUD Balangan meliputi harapan, kenyataan, dan kualitas pelayanan obat. Peneliti ini merupakan penelitian deskriptif. Sampel pada penelitian ini sebanyak 309 orang. Teknik pengumpulan data dilakukan dengan menggunakan kuesioner.Hasil penelitian menunjukan bahwa harapan pasien BPJS terhadap pelayanan obat di Depo Farmasi BLUD RSUD Balangan adalah termasuk dalam kriteria penting $(4,213)$, Persepsi pasien BPJS terhadap pelayanan obat di Depo Farmasi BLUD RSUD Balangan termasuk dalam kriteria puas $(4,118)$, Kualitas pelayanan obat pasien BPJS di Depo Farmasi BLUD RSUD Balangan termasuk dalam kriteria sedang $(\mathrm{GAP}=0,119)$.Berdasarkan hasil penelitian dapat disimpulkan bahwa harapan pasien termasuk dalam kriteria penting, kenyataan pasien termasuk dalam kriteria puas, dan kualitas pelayanan obat termasuk dalam kriteria sedang.
\end{abstract}

Kata Kunci : Kualitas, Pelayanan Depo Farmasi, BPJS, Rumah sakit.

\section{ABSTRACT}

Patient perception of care plays a very important, current level of increasingly fierce competition among enterprises Hospital requires the existence of competitiveness for the Hospital in order to win the competition. One form of competitiveness must be created by the efforts of the Hospital is the quality of service. The purpose of this study to determine the quality of drug services in Depo BLUDs Hospital Pharmacy Balangan is hope, reality, and the quality of drug services. This is a descriptive study investigators. Samples in this study as many as 309 people. Data collection techniques using questionnaires. The results showed that the quality of patient drug services BPJS in Hospital Pharmacy Installation BLUDs Balangan medium quality. Patient expectations BPJS against drug services in Depo Pharmaceuticals are included in the essential criteria (4.213), perception of patients BPJS against drug services in Depo Pharmacy included in the criteria are satisfied (4.118), Quality of care is the patient's drug BPJS in Depo Pharmacy BLUDs Balangan included in the criteria moderate $(\mathrm{GAP}=0.119)$. Based on the results of this study concluded that patient 
expectations are included in the patients included in the criteria are satisfied, and the quality of drug services included in the critetia for moderate.

Keywords : Quality, Service Drugs, Hospitals.

\section{PENDAHULUAN}

Salah satu bentuk daya saing yang harus diciptakan oleh usaha rumah sakit adalah kualitas layanan. Semakin tinggi tingkat pemahaman masyarakat terhadap pentingnya kesehatan untuk mempertahankan kualitas hidup, maka masyarakat pengguna akan semakin kritis dalam menerima produk jasa. Oleh karena itu, peningkatan kualitas layanan rumah sakit perlu terus menerus dilakukan (Gunawan, 2011).

Persepsi pasien tentang pelayanan memegang peranan yang sangat penting. Kualitas pelayanan akan terpenuhi apabila proses penyampaian jasa dari pemberi jasa kepada pasien sesuai dengan apa yang dipersepsikan oleh pasien. Ketika pelayanan yang baik telah diberikan oleh para karyawan akan terbentuk hubungan kekeluargaan. Hal ini akan berdampak pada tingkat loyalitas pelanggan. Hasil penelitian Sabihaini (2002) menyimpulkan bahwa dimensi daya tanggap berpengaruh terhadap tingkat loyalitas pasien.

Salah satu bentuk layanan rumah sakit yang penting adalah farmasi dalam pelayanannya dapat diberikan melalui depo-depo. Salah satunya adalah depo pelayanan obat BPJS (Syahrer, O. 2014).Rumah Sakit Balangan merupakan rumah sakit yang terbilang baru, karena kurang lebih baru sebelas tahun ini saja beroperasi. Hal ini terjadi karena Kabupaten balangan merupakan sebuah kabupaten pemekaran dari Hulu Sungai Utara. Letak rumah sakit ini berada di tengah kota akan tetapi jauh dari pemukiman warga. Sebagai mana diketahui biasanya rumah sakit yang tergolong baru, peralatan, pembangunan dan tenaga medis yang disediakan masih termasuk minim. Oleh sebab itu peneliti tertarik untuk meneliti bagaimana tingkat kualitas pelayanan obat pada pasien BPJS di Kabupaten tersebut.

\section{METODE PENELITIAN \\ Instrumen Penelitian}

Instrumen yang digunakan dalam penelitian ini berupa lembar kuesioner yang diberikan kepada pasien yang memenuhi kriteria inklusi dan ekslusi serta telah mengisi informed consent.

\section{Jalannya Penelitian}

Penelitian ini menggunakan metode deskriptif untuk membuat gambaran kualitas pelayanan obat pasien peserta BPJS di BLUD RSUD Balangan. Penelitian dilakukan di Depo Farmasi BPJS BLUD Rumah Sakit Umum Daerah Balangan pada periode Mei-Juni tahun 2016. Populasi dalam penelitian ini adalah jumlah rata-rata pasien yang mendapatkan pelayanan obat pada Depo BPJS di Instalasi Farmasi BLUD RSUD Balangan Pada Bulan Januari, Februari dan Maret tahun 2016 yaitu sebanyak 1.341 pasien. Sampel yang diambil dan diteliti adalah pasien yang mendapatkan pelayanan obat pada BPJS di Instalasi Farmasi BLUD RSUD Balangan pada periode Mei-Juni Tahun 2016 yang memenuhi kriteria inklusi dan ekslusi. Teknik pengambilan sampel yang digunakan yaitu purposive sampling. Jumlah populasi dalam penelitian ini telah diketahui sehingga pengambilan sampel yang digunakan dalam penelitian ini adalah rumus slovin (Nursalam 2008)

Rumus Slovin :

$$
\mathrm{n}=N d^{2}+1
$$

Keterangan :

$$
\begin{aligned}
& \mathrm{N}=\text { jumlahsampel } \\
& \mathrm{N}=\text { jumlahpopulasi } \\
& \mathrm{D}=\text { Presisi yang ditetapkan }(\mathrm{d}: 0,05)
\end{aligned}
$$

Dengan menggunakan rumus slovin 309 sampel dengan tingkat kesalahan 5\%. Data 
yang diperoleh dianalisis dengan menggunakan SPSS 16.00.

\section{HASIL DAN PEMBAHASAN HASIL}

Karakteristik responden menjawab pertanyaan yang di berikan peneliti didapat bahwa mayoritas responden yang berperan serta dalam penelitian ini berjenis kelamin perempuan sebanyak 179 responden $(53,76 \%)$, dengan mayoritas responden berpendidikan SLTA sebanyak 210 responden $(63,06 \%)$.

Pada data tersebut juga diketahui bahwa responden yang berperan serta dalam penelitian memiliki pekerjaan sebagai ibu rumah tangga sebanyak 86 responden $(25,82 \%)$ dan paling sedikit bekerja sebagai PNS sebanyak 17 responden $(5,10 \%)$, dan mayoritas responden berada pada golongan umur 21-30 responden (36,04\%).

Tabel I.Karakteristik Responden

\begin{tabular}{clcc}
\hline \multirow{2}{*}{ Karakteristik Pasien } & \multicolumn{2}{c}{ Subjek Peneliti } \\
\cline { 2 - 3 } Jenis Kelamin & Laki-Laki & $(\mathrm{n}=333)$ & $46,24 \%$ \\
& Perempuan & 154 & $53,76 \%$ \\
& Tidak Sekolah & 179 & $9,01 \%$ \\
& SD & 30 & $8,11 \%$ \\
\multirow{2}{*}{ Pendidikan } & SLTP & 27 & $8,11 \%$ \\
& SLTA & 27 & $63,06 \%$ \\
& Perguruan Tinggi & 210 & $11,71 \%$ \\
& PNS & 39 & $5,10 \%$ \\
& Swasta & 17 & $18,32 \%$ \\
& Pedagang & 61 & $19,82 \%$ \\
& Mahasiswa & 66 & $13,82 \%$ \\
& Buruh & 46 & $17,12 \%$ \\
& IRT & 57 & $25,82 \%$ \\
& $11-20$ & 86 & $9,61 \%$ \\
& $21-30$ & 32 & $36,04 \%$ \\
& $31-40$ & 120 & $18,62 \%$ \\
& $41-50$ & 62 & $19,52 \%$ \\
& $51-60$ & 65 & $11,71 \%$ \\
& $61-70$ & 39 & $4,50 \%$ \\
\hline
\end{tabular}

Sumber : Data Primer; Keterangan : $\mathrm{n}=$ jumlah sampel; $\%=$ jumlah total 
Tabel II. Penilaian harapan (ekspektasi) pasien BPJS terhadap pelayanan obat di Depo Farmasi BLUD RSUD Balangan

\begin{tabular}{|c|c|c|c|}
\hline Dimensi & No Soal & Rata-rata Harapan & Rara-rata \\
\hline \multirow{6}{*}{ 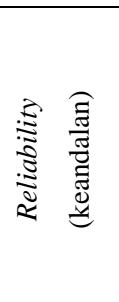 } & 1 & 4,339 & \multirow{6}{*}{4,339} \\
\hline & 2 & 4,693 & \\
\hline & 3 & 4,861 & \\
\hline & 4 & 4,846 & \\
\hline & 5 & 4,582 & \\
\hline & 6 & 4,516 & \\
\hline \multirow{4}{*}{ 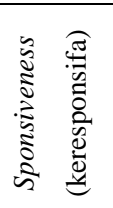 } & 7 & 4,453 & \multirow{4}{*}{4,396} \\
\hline & 8 & 4,426 & \\
\hline & 9 & 4,402 & \\
\hline & 10 & 4,396 & \\
\hline \multirow{4}{*}{ 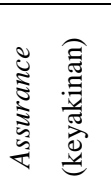 } & 11 & 4,651 & \multirow{4}{*}{4,327} \\
\hline & 12 & 4,366 & \\
\hline & 13 & 4,327 & \\
\hline & 14 & 4,222 & \\
\hline \multirow{4}{*}{ 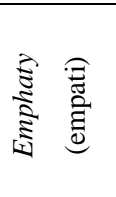 } & 15 & 4,096 & \multirow{4}{*}{4,096} \\
\hline & 16 & 4,015 & \\
\hline & 17 & 3,957 & \\
\hline & 18 & 3,978 & \\
\hline \multirow{5}{*}{ 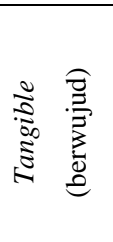 } & 19 & 3,915 & \multirow{5}{*}{3,558} \\
\hline & 20 & 3,846 & \\
\hline & 21 & 3,666 & \\
\hline & 22 & 3,369 & \\
\hline & 23 & 2,993 & \\
\hline & & RATA-R & \\
\hline
\end{tabular}

Penilaian harapan (ekspektasi) pasien BPJS terhadap pelayanan obat di Depo Farmasi BLUD RSUD Balangan dengan ( $\mathrm{N}=333)$. Berdasarkan data tersebut, dapatdilihat rata-rata harapanrespondenterhadappelayananobat di DepoFarmasi BLUD RSUD Balanganaalahsebesar 4,213 (Tabel II).

Penilaian kenyataan (persepsi) pasien BPJS terhadap pelayanan obat di Depo Farmasi BLUD RSUD Balangan dengan ( $\mathrm{N}=333$ ).Berdasarkan data tersebut, dapatdilihat rata-rata kenyataanrespondenterhadappelayananobat di DepoFarmasi BLUD RSUD Balanganadalahsebesar 4,118 (Tabel III).

Pada bagian ini menjelaskan bagaimana seorang pasien menilai kualitas pelayanan yang diberikan, berdasarkan atas terpenuhi atau tidaknya harapan pasien, yang akhirnya akan menentukan tingkat kepuasan pasien tersebut. Pada konteks ini pengukuran mengenai kualitas pelayanan obat merupakan perbandingan antara pelayanan yang diharapkan dengan pelayanan obat yang diterima. Jika persepsi layanan sama atau lebih besar dari harapan pasien, maka pelayanan obat di BLUD RSUD Balangan akan memperoleh citra dan dampak positif. Namun, jika persepsi layanan lebih rendah dari yang diharapkan maka pelayanan obat belum mampu memberikan kepuasan secara maksimal. 
Tabel III. Penilaian kenyataan (persepsi) pasien BPJS terhadap pelayanan obat di Depo Farmasi BLUD RSUD Balangan

\begin{tabular}{|c|c|c|c|}
\hline Dimensi & No Soal & Rata-rata Kenyataan & Rata-rata \\
\hline \multirow{6}{*}{ 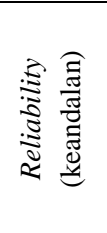 } & 1 & 4,012 & \multirow{6}{*}{4,012} \\
\hline & 2 & 4,387 & \\
\hline & 3 & 4,927 & \\
\hline & 4 & 4,861 & \\
\hline & 5 & 4,699 & \\
\hline & 6 & 4,579 & \\
\hline \multirow{4}{*}{ 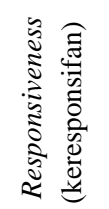 } & 7 & 4,423 & \multirow{4}{*}{4,057} \\
\hline & 8 & 4,285 & \\
\hline & 9 & 4,096 & \\
\hline & 10 & 4,057 & \\
\hline \multirow{4}{*}{ 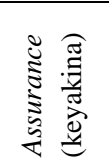 } & 11 & 4,291 & \multirow{4}{*}{4,003} \\
\hline & 12 & 4,045 & \\
\hline & 13 & 4,003 & \\
\hline & 14 & 3,945 & \\
\hline \multirow{4}{*}{ 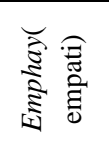 } & 15 & 3,978 & \multirow{4}{*}{3,978} \\
\hline & 16 & 3,921 & \\
\hline & 17 & 3,948 & \\
\hline & 18 & 3,924 & \\
\hline \multirow{5}{*}{ 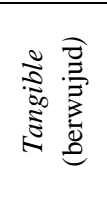 } & 19 & 3,867 & \multirow{5}{*}{3,670} \\
\hline & 20 & 3,828 & \\
\hline & 21 & 3,039 & \\
\hline & 22 & 3,810 & \\
\hline & 23 & 3,807 & \\
\hline & & \multicolumn{2}{|c|}{ RATA-RATA $=4,118$} \\
\hline
\end{tabular}

Tabel IV.Klasifikasi kualitas berdasarkan nilai GAP

\begin{tabular}{ccccc}
\hline Kualitas & \multicolumn{4}{c}{ Nilai Kesenjangan $(\mathrm{GAP})$} \\
\hline Buruk & $>$ & 0,626 & dan & $\leq 0,982$ \\
Kurang & $>$ & 0,271 & dan & $\leq 0,626$ \\
Sedang & $>$ & $-0,083$ & dan & $\leq 0,271$ \\
Cukup & $>$ & $-0,438$ & dan & $\leq-0,083$ \\
Baik & $>$ & $-0,794$ & dan & $\leq-0,438$ \\
\hline
\end{tabular}

Dalam pengolahan data dilihat nilai rata-rata skor setiap butir pertanyaan pada aspek harapan dan kenyataan responden, selanjutnya dihitung kesenjangan (GAP) antara harapan dan kenyataan yang diterima responden. Formulasi kesenjangan dalam hal merupakan nilai yang didapat dari kesenjangan GAP sebagai berikut, GAP $=($ Harapan Kenyataan).

Tabel V.Kualitas Pelayanan Obat berdasarkan masing-masing dimensi

\begin{tabular}{lcccc}
\hline \multicolumn{1}{c}{ Dimensi } & Harapan & Kenyataan & Gap & Kualitas \\
\hline Reliability & 4,339 & 4,012 & 0,327 & Kurang \\
Responsiveness & 4,396 & 4,057 & 0,339 & Kurang \\
Assurance & 4,327 & 4,003 & 0,324 & Kurang \\
Emphaty & 4,096 & 3,978 & 0,118 & Sedang \\
Tangible & 3,558 & 3,670 & $-0,112$ & Cukup \\
Rata-rata & 4,143 & 3,944 & 0,199 & Sedang \\
\hline
\end{tabular}


Pada penelitian ini dilakukan analisis uji beda yang bertujuan untuk mengetahui apakah ada perberdaan antara pelayanan yang diharapkan dengan kenyataan yang dirasakanoleh pasien, untuk mengetahui uji apa yang digunakan maka terlebih dahulu dilakukan uji normalitas dan homogenitas. Hasil uji normalitas (kolmogorov-Smirnof) dan uji homogenitas( levene test ) menunjukan bahwa data tidak terdistribusi normal dan homogen $(\mathrm{p}<0,05)$ sehingga di lakukan uji non parametrik berupa uji wilcoxon. Hasil uji yang diperoleh nilai signifikasi $0,000(\mathrm{p}<0,005)$ menunjukan bahwa terdapat perbedaan yang bermakna antara harapan dan kenyataan.

\section{KESIMPULAN}

Berdasarkan hasil penelitian di Depo Farmasi BLUD RSUD Balangan pada periode Mei-Juni Tahun 2016, dengan jumlah pasien 333 orang dapat dibuat kesimpulan sebagai berikut :Harapanpasien BPJS terhadap pelayanan obat termasuk dalam kriteria penting (4,213); Persepsi pasien BPJS terhadap pelayanan obat termasuk dalam kriteria puas (4,118); Kualitas pelayanan obat pasien BPJS termasuk dalam kriteria sedang $(\mathrm{GAP}=0,199)$. Dari hasil yang didapat yang memiliki nilai terendah yaitu dimensi reliability, responsiveness, dan assurance dengan kategori kurang.

\section{DAFTAR PUSTAKA}

Gunawan, Ketut. 2011. "Kualitas Layanan dan Loyalitas Pasien (Studi pada Rumah Sakit Umum Swasta di Kota Singaraja-Bali)”. Universitas Panji SaktiSingaraja. Bali.

Nursalam. 2008. Konsep dan penerapan metodologi penelitian keperawatan. Jakarta

Sabihaini. 2002. "Analisis Konsekuensi Keperilakuan Kualitas Layanan: Suatu Kajian Empirik", Usahawan, hal: 29-36.

Syahrer, O. 2014. Gambaran Kualitas Pelayanan Obat Pada Pasien di depo BPJS Rawat Jalan RSUD Ratu Zalecha Martapura.Karya Tulis Ilmiah, Akademi Farmasi ISFI Banjarmasin, Banjarmasin. 